\title{
Contrasting organic aerosol particles from boreal and tropical forests during HUMPPA-COPEC-2010 and AMAZE-08 using coherent vibrational spectroscopy
}

\author{
C. J. Ebben ${ }^{1}$, I. S. Martinez ${ }^{1}$, M. Shrestha ${ }^{1}$, A. M. Buchbinder ${ }^{1}$, A. L. Corrigan $^{2}$, A. Guenther ${ }^{3}$, T. Karl ${ }^{3}$, T. Petäjäa ${ }^{4}$, \\ W. W. Song ${ }^{5}$, S. R. Zorn ${ }^{6}$, P. Artaxo ${ }^{7}$, M. Kulmala ${ }^{4}$, S. T. Martin ${ }^{6}$, L. M. Russell ${ }^{2}$, J. Williams ${ }^{5}$, and F. M. Geiger ${ }^{1, *}$ \\ ${ }^{1}$ Department of Chemistry, Northwestern University, 2145 Sheridan Road, Evanston, IL 60208, USA \\ ${ }^{2}$ Scripps Institution of Oceanography and the University of California, San Diego, La Jolla, CA 92093, USA \\ ${ }^{3}$ Earth System Laboratory, National Center for Atmospheric Research, Boulder, CO 80307, USA \\ ${ }^{4}$ Department of Physics, 00014, University of Helsinki, Finland \\ ${ }^{5}$ Max Planck Institute for Chemistry, 55128 Mainz, Germany \\ ${ }^{6}$ School of Engineering and Applied Sciences \& Department of Earth and Planetary Sciences, Harvard University, 29 Oxford \\ Street, Cambridge, MA 02138, USA \\ ${ }^{7}$ Institute of Physics, University of São Paulo, Rua do Matão, Travessa R, 187, 05508-090, São Paulo, Brazil
}

Received: 27 May 2011 - Published in Atmos. Chem. Phys. Discuss.: 17 June 2011

Revised: 14 September 2011 - Accepted: 28 September 2011 - Published: 17 October 2011

\begin{abstract}
We present the vibrational sum frequency generation spectra of organic particles collected in a boreal forest in Finland and a tropical forest in Brazil. These spectra are compared to those of secondary organic material produced in the Harvard Environmental Chamber. By comparing coherent vibrational spectra of a variety of terpene and olefin reference compounds, along with the secondary organic material synthesized in the environmental chamber, we show that submicron aerosol particles sampled in Southern Finland during HUMPPA-COPEC-2010 are composed to a large degree of material similar in chemical composition to synthetic $\alpha$-pinene-derived material. For material collected in Brazil as part of AMAZE-08, the organic component is found to be chemically complex in the coarse mode but highly uniform in the fine mode. When combined with histogram analyses of the isoprene and monoterpene abundance recorded during the HUMPPA-COPEC-2010 and AMAZE-08 campaigns, the findings presented here indicate that if air is rich in monoterpenes, submicron-sized secondary aerosol particles that form under normal $\mathrm{OH}$ and $\mathrm{O}_{3}$ concentration levels can be described in terms of their hydrocarbon content as being similar to $\alpha$-pinene-derived model secondary or-
\end{abstract}

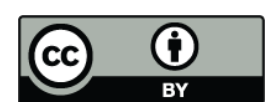

Correspondence to: F. M. Geiger (geigerf@chem.northwestern.edu) ganic aerosol particles. If the isoprene concentration dominates the chemical composition of organic compounds in forest air, then the hydrocarbon component of secondary organic material in the submicron size range is not simply wellrepresented by that of isoprene-derived model secondary organic aerosol particles but is more complex. Throughout the climate-relevant size range of the fine mode, however, we find that the chemical composition of the secondary organic particle material from such air is invariant with size, suggesting that the particle growth does not change the chemical composition of the hydrocarbon component of the particles in a significant way.

\section{Introduction}

Plants in boreal and tropical forests emit pinene, isoprene, and related terpenes, and these volatile compounds undergo atmospheric oxidation reactions. A portion of the oxidation products partitions into the particle phase as secondary organic material. In general, isoprene is the main gas phase emission found in tropical forests, whereas $\alpha$-pinene is often the most abundant biogenic volatile organic compound in boreal forests. These two types of forest were the focus of two recent field campaigns, namely HUMPPA-COPEC2010, which was conducted in Southern Finland (Williams

Published by Copernicus Publications on behalf of the European Geosciences Union. 
et al., 2011), and AMAZE-08, which was conducted in the central Amazon basin (Martin et al., 2010). Here, we show how the chemical identity of the aerosol particle phase sampled in forest air can be evaluated directly, and without the need for solid phase extraction or other sample manipulation, with a table-top laser spectroscopic method that probes sub-nanogram amounts of particle material collected on impactor and filter samples. Specifically, we use the coherent second-order nonlinear vibrational spectroscopy sum frequency generation (SFG) (Zhu et al., 1986; Guyot-Sionnest et al., 1987a) to study organic aerosol particles from a boreal and a tropical forest and compare the results to SFG responses obtained from synthetic organic aerosol particles prepared in an environmental chamber. SFG is forbidden in centrosymmetric media, which means that it is a surfacespecific technique for achiral systems. We also present vibrational SFG spectra of hydrocarbon reference compounds relevant for the study of biogenic volatile organic compounds and their conversion to secondary organic aerosol particles.

SFG has become a popular method for addressing scientific questions regarding heterogeneous atmospheric chemistry in laboratory model systems consisting of surfaces of flat oxide solids functionalized with atmospherically relevant molecules (Konek et al., 2004; Voges et al., 2005a, 2007b; Geiger, 2009; Stokes et al., 2009a, b, c), and of liquids, notably water (Allen et al., 1999; Liu et al., 2004; Mucha et al., 2005; Gopalakrishnan et al., 2006; Tarbuck et al., 2006; Voss et al., 2007). Hallmarks of the method are an exquisite sensitivity to molecular structure within complex environments, a very high selectivity for environments where symmetry is broken, and intrinsic heterodyne detection of weak vibrational responses, which allows for the analysis of nanoand sub-nanogram amounts of sample. SFG should therefore be an appropriate method of choice for studying the chemical composition of natural and synthetic terpene-derived aerosol particles, which we test here on organic aerosol particles sampled in Southern Finland and in the central Amazon basin.

The particles from Southern Finland were collected during HUMPPA-COPEC measurements, which were conducted from 12 July 2010 to 12 August 2010 at the Boreal forest research station near Hyytiälä, Finland. The measurement period was characterized by anomalously high temperature (ten days between 25 and $32^{\circ} \mathrm{C}$ ). The relative humidity ranged from $30-60 \%$ during the night and from $80 \%$ to $100 \%$ during daytime, while NO concentrations were in the $0.1 \mathrm{ppb}$ range. The $\mathrm{O} / \mathrm{C}$ ratio, as determined by FTIR and aerosol mass spectrometry (AMS), ranged between 0.5 and 0.7 for the duration of the campaign. The presence of Scots pine, Norway spruce, birch, conifers, willows, and aspen make the site representative of the Boreal forest ecosystem, with the sum of $\alpha$ - and $\beta$-pinene and carene concentrations exceeding isoprene concentrations in 287 out of 341 measurements. $\mathrm{OH}$ concentrations ranged from 0.2 to $3 \times 10^{6} \mathrm{cc}^{-1}$ and ozone concentrations were high, ranging from 20 to $70 \mathrm{ppb}$ (see Ta- ble 1). The particles from the central Amazon basin were collected following AMAZE-08, from 9 April 2008 to 17 April 2008, principally at research tower TT34, which is located approximately $60 \mathrm{~km}$ NNW of Manaus, Brazil. The air sampled during the campaign was pristine, as the work was carried out during the wet season and outside of appreciable influence of biomass burning events or inputs from African dust (Martin et al., 2010). The temperature at the top of the research tower ranged from $22-32^{\circ} \mathrm{C}$, while the relative humidity ranged from as low as $60 \%$ at night time to $100 \%$ during the day. The NO concentrations during AMAZE-08 were in the $0.1 \mathrm{ppb}$ range, and the $\mathrm{O} / \mathrm{C}$ ratio, as determined by the Harvard AMS, was $0.4 \pm 0.1$ for the entire campaign. With concentrations of up to $8 \mathrm{ppb}$, isoprene was the dominant terpene in the gas phase during AMAZE-08, while $\alpha$-pinene represented, on average, half of the remaining terpene budget (see Table 1). Three other studies provide evidence that leads us to conclude that $\mathrm{OH}$ concentrations are generally high enough to dominate the oxidative chemistry of the terpenes (Karl et al., 2007; Lelieveld et al., 2008). The negligible anthropogenic contributions make the AMAZE-08 measurements relevant for benchmarking the HUMPPA-COPEC field measurements against the production of nearly pure biogenic aerosol particles under preindustrial conditions in a tropical forest. In addition, the extensive datasets available for the particle and the gas phases of atmospheric aerosol sampled at the two locations provide key fundamental information for introducing coherent vibrational laser spectroscopic methods to atmospheric chemistry and physics with the goal of deepening our understanding of the formation, microphysics, and fate of aerosol particles in tropical vs. boreal forests.

\section{Measurements}

\subsection{Particle sampling}

The HUMPPA-COPEC-2010 filters studied in the work presented here were loaded and exposed to ambient air from an inlet for a period of $24 \mathrm{~h}$ starting around 06:00 a.m. LT on 17, 21 and 23 July 2010. Conditions during those three days at the site were characterized by clear weather, negligible precipitation, and an absence of biomass burning tracers. NOAA HYSPLIT model calculations of $72 \mathrm{~h}$ back trajectories indicate that the sampled air masses originated predominantly from the North to Northwest, i.e. Northwestern Scandinavia, for 17 and 23 July, but from the SW, i.e. Northwestern Europe, for 21 July 2010. In order to collect particulate matter smaller than $1 \mu \mathrm{m}$, a cyclone was used, after which the particles were sent through a dryer and collected onto Teflon air sampling membranes (PTFE, VWR, $37 \mathrm{~mm}$, $1 \mu \mathrm{m}$ pores, catalog number: $28150-400)$ using a controlled flow of 16.7 SLPM. This resulted in organic mass loadings, determined by FTIR spectroscopy, of 21.8, 19.5, and $2.5 \mu \mathrm{g}$ 
Table 1. Range of concentrations of temperature, relative humidity, $\mathrm{OH}, \mathrm{O}_{3}$ various monoterpenes, and $\mathrm{O} / \mathrm{C}$ ratio relevant in Southern Finland and the central Amazon Basin.

\begin{tabular}{lcc}
\hline Species & Southern Finland & Central Amazon basin \\
\hline Temperature $\left[{ }^{\circ} \mathrm{C}\right]$ & 25 (night) to 32 (day) & 22 (night) to 32 (day) \\
$\mathrm{RH}[\%]$ & $30-60$ (night) to $80 \%-100 \%$ (day) & 60 (night) to 100 (day) \\
$\mathrm{OH}\left[10^{6} \mathrm{~cm}^{-3}\right]$ & $0.2-3.0$ & $1-3^{*}$ and $5 * *$ \\
$\mathrm{NO}[\mathrm{ppb}]$ & 0.1 & 0.1 \\
$\mathrm{O}_{3}[\mathrm{ppb}]$ & $20-70$ & $1-20$ \\
Isoprene $[\mathrm{ppb}]$ & $0.01-0.70$ & $1-9$ \\
$\alpha-$ pinene $[\mathrm{ppb}]$ & $0.01-1.0$ & $0.01-0.40$ \\
$\beta-$ pinene $[\mathrm{ppb}]$ & $0.01-0.20$ & $0.008-0.080$ \\
Limonene $[\mathrm{ppb}]$ & n.a. & $0.008-0.080^{*}$ \\
$\mathrm{O} / \mathrm{C}$ ratio & 0.5 to 0.7 & $0.4+/-0.1$ \\
\hline
\end{tabular}

* Data for the same location studied during AMAZE-08 from Karl etal. (2007)

** Data for the tropical forest boundary layer from Lelieveld et al. (2008)

for the three filters studied here. The first two filters were collected during a time when the sum of the gas phase concentrations of isoprene, $\alpha$ - and $\beta$-pinene, and carene were as high as $1.55 \mathrm{ppb}$ and $0.36 \mathrm{ppb}$, respectively. Specifically for the day of the first filter (17 July 2010), sawmill activity near the sampling site resulted in monoterpene concentrations six times larger than background. In contrast, the last filter was collected during a time when the terpene concentration was near $0.05 \mathrm{ppb}$, the lowest during the campaign, with all available data suggesting that the last filter sampled air during a nucleation event. In all cases, the sum of $\alpha$ - and $\beta$-pinene concentrations exceeded that of isoprene and carene by a factor of up to two. We note that noteworthy anthropogenic events did not occur (Williams et al., 2011) on the days of filter collection relevant for this current manuscript $(17,21$, and 23 July 2010) except for the sawmill event on 17 July.

The aerosol particles collected in the central Amazon basin were sampled using a micro-orifice uniform-deposit impactor (MOUDI) (Marple et al., 1991) loaded with Whatman Nucleopore filters having $0.4 \mu \mathrm{m}$ pore size. The MOUDI samples studied in this work were collected one month after the conclusion of AMAZE-08 during a time of 8 days (9 April 2008 to 17 April 2008). Conditions during the time of MOUDI sampling were characterized by daily cloud cover and regular thunderstorms, with northeasterly winds dominating. NOAA HYSPLIT backtrajectory calculations indicate the air samples during AMAZE-08 originated mainly out of the NE, covering roughly $2000 \mathrm{~km}$ of pristine tropical forest prior to arrival at tower TT34 (Martin et al., 2010). There was minimal input from biomass burning or African dust during this time (Martin et al., 2010). The analysis of aerosol particles sampled during measurements that followed the AMAZE-08 campaign indicates that the chemical composition of the aerosol particle phase across the fine and the coarse modes was consistent during the 2008 wet season, which includes the months of February, March, and
April. It is therefore reasonable to assume that the gas phase concentration and speciation conditions determined during AMAZE-08, during which isoprene concentrations reached up to $8 \mathrm{ppb}$, while $\alpha$ - and $\beta$-pinene, d-limonene, cymene, camphene, sabinene, ocimene, cymenene, myrcene, tricyclene, carene, and phellandrene were present at five to ten times lower concentrations, are applicable to the time of MOUDI sampling. The $50 \%$ aerodynamic-diameter cutoff points for the various MOUDI stages are, after an 18-micron cut-point inlet, 10.0, 5.6, 3.2, 1.8, 1.0, 0.6, 0.3, 0.2 and $0.1 \mu \mathrm{m}$, followed by an after-filter that collects the remaining material. The MOUDI samples contained 1.016, 0.257, and $0.150 \mathrm{mg}$ of material for the $3.2,1.0$, and $0.3 \mu \mathrm{m}$ size ranges, which are the ones investigated in this work. The mass loadings of the MOUDI samples from AMAZE-08 are more than an order of magnitude larger than those of the filters collected during HUMPPA-COPEC-2010 (vide supra). The fraction of elemental carbon, a marker for biomass burning, is 63.0, 3.2, and $16.0 \%$ of the collected mass on each MOUDI stage for those size ranges, respectively.

\subsection{Synthesis of secondary organic aerosol particle model compounds from $\alpha$-pinene and isoprene}

As a point of comparison to the natural samples from the Central Amazon Basin and Southern Finland, we prepared synthetic model SOA material from the oxidation of isoprene (Air Liquide, 2-methyl-1, 3-butadiene, $50 \mathrm{ppm} \pm 5 \%, \mathrm{~N}_{2}$ balanced) and $\alpha$-pinene (Aldrich, (+)- $\alpha$-pinene, $98 \%$ enantiomeric excess and $98.5 \%$ to $99.7 \%$ chemical purity) in the Harvard Environmental Chamber (Shilling et al., 2008). The chamber was operated as a continuous-flow tank reactor using inorganic seed particles that were produced by nebulizing an ammonium sulfate solution (Sigma TraceSELECT, 99.9999\%) with an atomizer (TSI, Model 3076). The polydisperse aerosol produced by the atomizer was 
first diffusion-dried to $<10 \%$ relative humidity to dry the particles and then size selected by a differential mobility analyzer (DMA; TSI, Model 3070). The temperature was kept constant at $25.2^{\circ} \mathrm{C} \pm 0.2^{\circ} \mathrm{C}$.

For the preparation of isoprene-derived organic aerosol particle models, monodisperse seed particles of $30 \mathrm{~nm}, 50 \mathrm{~nm}$ or $70 \mathrm{~nm}$ were injected into the chamber, followed by injection of hydrogen peroxide $\left(\mathrm{H}_{2} \mathrm{O}_{2}\right)$ as an $\mathrm{OH}$ precursor by bubbling Nitrogen (Airgas, Ultra High Purity Grade (5.0)) through a gas-washing bottle filled with a $50 \%$ hydrogen peroxide solution (Sigma-Aldrich, 50 wt. $\%$ in $\mathrm{H}_{2} \mathrm{O}$ ). $(C A U$ TION: hydrogen peroxide can be explosive. Care needs to be taken as outlined in the MSDS when working with this compound.) An ozone monitor was used to estimate the $\mathrm{H}_{2} \mathrm{O}_{2}$ concentration. $\mathrm{H}_{2} \mathrm{O}_{2}$ shows a small absorption at the operation wavelength of the ozone monitor $(254 \mathrm{~nm})$. By using the absorption cross-section of $\mathrm{H}_{2} \mathrm{O}_{2} \sim\left(s_{\mathrm{H}_{2} \mathrm{O}_{2}}=-6.7 e^{-20}\right.$; $254 \mathrm{~nm}, 298 \mathrm{~K}$; (Sander et al., 2011)) the $\mathrm{H}_{2} \mathrm{O}_{2}$ concentration can be calculated. For an apparent ozone concentration of $76.4 \mathrm{ppb} \pm 13.9 \mathrm{ppb}$ (standard deviation) the resulting $\mathrm{H}_{2} \mathrm{O}_{2}$ concentration is around $13.1 \mathrm{ppm}$. Under the experimental conditions, the fraction of ozone produced as a byproduct in the chamber is small compared to the $\mathrm{H}_{2} \mathrm{O}_{2}$ concentration in the gas phase. Under the experimental conditions, the fraction of ozone produced as a byproduct in the chamber is small compared to the $\mathrm{H}_{2} \mathrm{O}_{2}$ concentration in the gas phase. The experimental runs were initiated once the concentrations of $\mathrm{H}_{2} \mathrm{O}_{2}$, terpene, seed particles, and the relative humidity were in steady state by turning on an array of UV lights in the chamber (BL350 OSRAM having $350 \mathrm{~nm}$ peak output) to begin the production of $\mathrm{OH}$ radicals $\left(7 \times 10^{6} \mathrm{~cm}^{-3}\right.$, Chen et al., 2011) from $\mathrm{H}_{2} \mathrm{O}_{2}$ photolysis. The resultant photooxidation of isoprene led to reaction cascades that led to the formation of organic mass on the seed particles. After reaching steady state with respect to particle formation, conditions in the chamber were kept stable for several days, allowing sampling of filters for up $96 \mathrm{~h}$ with a flow rate of approximately 8 SLPM. During this time period the humidity inside the chamber was $40.0 \% \pm 0.8 \%$, and the temperature was kept constant at $25^{\circ} \mathrm{C} \pm 1{ }^{\circ} \mathrm{C}$. $\mathrm{NO}$ and $\mathrm{NO}_{\mathrm{x}}$ concentrations were below the detection limit of $1 \mathrm{ppb}$ (Teledyne $\mathrm{NO}_{\mathrm{x}}$ analyzer) at all times. The isoprene-derived particles were produced with an initial isoprene concentration of $200 \mathrm{ppb}$, and more than half of the isoprene reacted as verified by GC-FID measurements. This experiment used $50 \mathrm{~nm}$ seed particles, and the geometric mean diameter of the particles exiting the chamber was around $130 \mathrm{~nm}$, with an organic particle mass concentration of $(28.2 \pm 3.7) \mu \mathrm{g} \mathrm{m}^{-3}$.

The $\alpha$-pinene-derived particles were produced from the oxidation of $23 \pm 2 \mathrm{ppb} \alpha$-pinene stereoisomers and $300 \pm 15 \mathrm{ppb}$ of ozone at $25.0 \pm 0.1^{\circ} \mathrm{C}, 40 \pm 1 \%$ relative humidity, and low $\mathrm{NO}_{\mathrm{x}}(<1 \mathrm{ppb})$. The particles grew to a geometric mean diameter of $93 \mathrm{~nm}$ with a geometric standard deviation of $1.57 \mathrm{~nm}$ on ammonium sulfate seed particles that had an initial geometric mean diameter of $50 \mathrm{~nm}$ with a ge- ometric standard deviation of $1.23 \mathrm{~nm}$ during a period of at least $24 \mathrm{~h}$, given that properties of chamber-generated aerosol particles differ markedly from ambient particles if not left to process for a such an amount of time (Holzinger et al., 2010). The organic particle mass concentration was $16 \mathrm{mg}$ $\mathrm{m}^{-3}$. The particles were collected for $48 \mathrm{~h}$ on Teflon filters (Sartorius, PTFE, part \# 11807-47-N, $200 \mathrm{~nm}$ pore size), from the continuous outflow of the chamber at a sampling flow of 6 SLPM. For control samples, particles were removed prior to sampling by the use of a HEPA filter (Pall HEPA capsule, part \# 12144). Studies using filter blanks were carried out as well.

\subsection{SFG theory}

Surfaces or interfaces are noncentrosymmetric media in which two incident electric fields (E-fields) can generate a new E-field oscillating at the sum of the frequencies of the two incident E-fields without contribution from the centrosymmetric bulk phases adjacent to the surface or interface under investigation. SFG resonance enhancement occurs when the oscillators of interest are associated with a frequency that matches any of the frequencies of the three Efields. Vibrational SFG spectra are obtained by overlapping visible (typically $800 \mathrm{~nm}$ ) and infrared laser pulses at a sample of interest in space and time and recording the SFG signal intensity, which, depending on the wavelength of the infrared laser pulse, occurs between 600 and $700 \mathrm{~nm}$. Polarization selection is important in the experiments, and our current work uses a polarization combination in which we sample the component of the vibrational transition dipole moments that is aligned along the surface normal (Esenturk et al., 2004b) because it provided the greatest signal-to-noise in the acquired spectra. Equation (1) is relevant for determining the magnitude of the SFG response in our experiments:

$I_{\mathrm{SFG}} \propto\left|\chi_{\mathrm{NR}}^{(2)} e^{i \gamma_{\mathrm{NR}}}+\sum_{\nu=1}^{n} \chi_{R \nu}^{(2)} e^{i \gamma_{\nu}}\right|^{2} I_{\mathrm{vis}} I_{\mathrm{IR}}$

Here, $I_{\mathrm{SFG}}$ is the intensity of the SFG signal and $I_{\mathrm{vis}}$ and $I_{\mathrm{IR}}$ are the intensities of the visible and IR light fields, respectively. The square modulus contains the sum of non-resonant and resonant contributions to the second-order susceptibility, $\chi_{\mathrm{NR}}^{(2)}$ and $\chi_{R v}^{(2)}$, respectively, the latter of which is summed over all vibrational modes, $v$, while $\gamma$ represents the phase factors associated with both the non-resonant background and the vibrational modes. In general, $\chi_{R v}^{(2)}$ is modeled as the product of the number of oscillators in the noncentrosymmetric environment that yields signal, $N_{\mathrm{ads}}$, and the molecular hyperpolarizability, $\beta_{\nu}$, averaged over all molecular orientations of the oscillators (Eq. 2):

$\chi_{R \nu}^{(2)}=N_{\mathrm{ads}}\left\langle\beta_{\nu}\right\rangle$

As discussed in the previous paragraph, the value of the molecular hyperpolarizability increases when the frequency 
of the incoming IR pulse matches a vibrational transition intrinsic to the molecular species of interest. The orientational averaging is important because it shows that the SFG response of oscillators with a non-zero molecular hyperpolarizability can be zero if they are randomly oriented in three dimensions, such as the bulk of a gas or an isotropic liquid. At the interface between two such environments, symmetry is broken, molecules may have a net orientation, and nonlinear optical signals can be generated. The distribution of molecular orientations of a given set of oscillators, for example those at the SOA particle surface, can be readily determined using SFG (Esenturk et al., 2004b; Wang et al., 2005; Weeraman et al., 2006; Chen et al., 2007; Tyrode et al., 2008). Achiral molecules in centrosymmetric environments, be they liquid or solid, do not contribute to the SFG response. SFG responses obtained from such molecules therefore originate from the aerosol particle surface. Chiral molecules do not possess a center of inversion, and, using the proper polarization combination, their SFG responses can be nonzero and originate from the surface and the bulk of the aerosol particle, depending on symmetry. Details regarding the role of chirality in SOA particles are discussed in our recently published work (Ebben et al., 2011; Martinez et al., 2011). We emphasize that the present work is carried out using the SSPpolarization combination, which is insensitive to molecular chirality and yields SFG signals from the $\mathrm{CH}$ oscillators that are located at the surface of the aerosol particles as opposed to those that are located in the bulk.

\subsection{Laser system and data acquisition and sample cells}

As shown in Fig. 1a, we use a broadband infrared source for our SFG experiments (Voges et al., 2005b, 2007b; Hayes et al., 2009; Stokes et al., 2009a, c). Briefly, a regeneratively amplified Ti:sapphire laser (Spitfire Pro, Spectra Physics) produces $\sim 120 \mathrm{fsec}$ pulses of $800 \mathrm{~nm}$ wavelength at a $1 \mathrm{kHz}$ repetition rate. The beam is passed through a 50/50 beam splitter, and half is used to pump an optical parametric amplifier (OPA-800CF, difference-frequency mixing option, Spectra Physics) in order to generate a broadband $\left(\sim 140 \mathrm{~cm}^{-1}\right.$ FWHM) IR pulse centered at $\sim 3.4 \mu \mathrm{m}$, which is used to probe the $\mathrm{C}-\mathrm{H}$ stretching region. The IR beam is focused onto the sample by a $\mathrm{BaF}_{2}$ lens (ISP Optics). The remaining $800 \mathrm{~nm}$ beam passes through a home-built delay stage to ensure it is temporally overlapped with the IR pulse when it reaches the sample. The $800 \mathrm{~nm}$ beam then passes through a narrow band-pass filter (F1.1-800.0-UNBLK-1.00, CVI Melles Griot), which spectrally narrows the $800 \mathrm{~nm}$ pulses to allow for a spectral resolution of around $10 \mathrm{~cm}^{-1}$ and an achromatic half-waveplate (MWPAA2-12-700-1000, Karl Lambrecht Corp.), which is used to rotate the plane of polarization before reaching the sample. The S-polarized $800 \mathrm{~nm}$ beam and P-polarized IR beam are incident on the sample interface at angles of $45^{\circ}$ and $60^{\circ}$ from normal and pulse energies of $0.1-2.0 \mu \mathrm{J}$ and $1 \mu \mathrm{J}$, respectively. The polarization

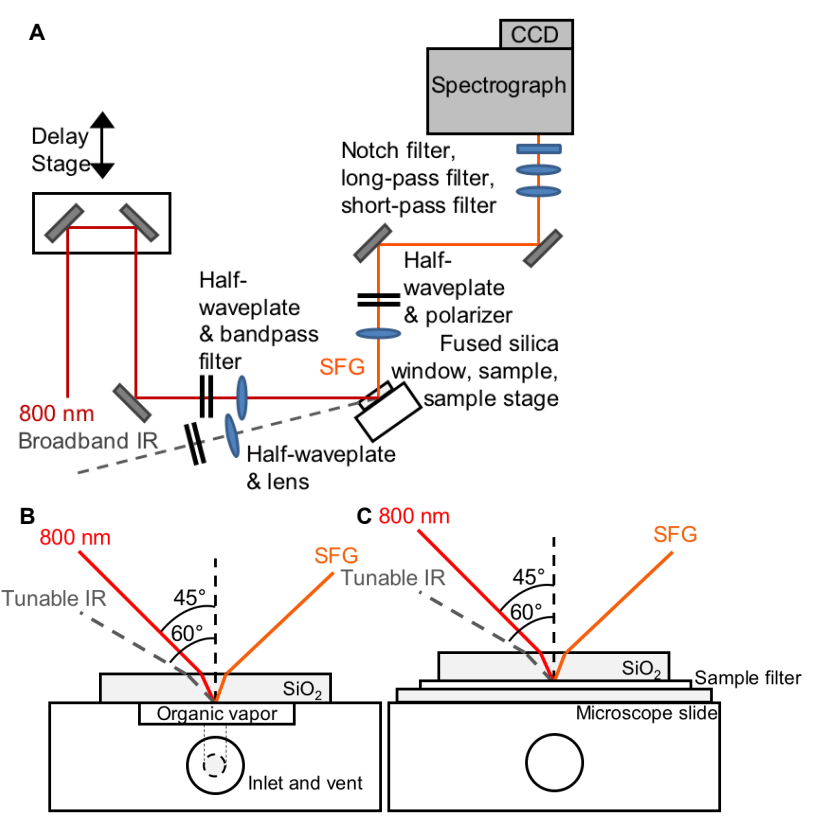

Fig. 1. (A) Schematic of the optical layout used for the vibrational sum frequency generation (SFG) experiments. (B) Top view of the sample cell used for collecting vibrational SFG spectra from the optical window/organic vapor interface. (C) Top view of the sample cell used for collecting vibrational SFG spectra from the fused silica/filter sample interface.

of the output SFG beam is selected by a Glan laser polarizer (GL15, Thorlabs), and a half-waveplate (MWPAA2-12-400700, Karl Lambrecht Corp.) rotates the SFG polarization in order to maximize the signal at the detector. A $600 \mathrm{~nm}$ long-pass filter, a short-pass filter and an $800 \mathrm{~nm}$ notch filter (Notch Plus Filter, Kaiser Optical Systems, Inc.) are used to remove output light resulting from processes other than SFG. A spectrograph (Acton Research) coupled to a liquid nitrogen cooled, back-thinned, charge coupled device camera (Roper Scientific, $1340 \times 100$ pixels) is used to detect the SFG signal. We account for the optical scatter of the $800 \mathrm{~nm}$ upconverter by blocking the IR input and collecting background spectra, which are subtracted from the SFG spectra. All SFG spectra are normalized to the non-resonant SFG spectrum of a gold-coated IR grade fused silica window, using a hybrid broadband-scanning method (Esenturk et al., 2004b) to account for the line shape of the incident broadband IR pulse. Spectra are calibrated using the SFG spectrum of a $70 \mu \mathrm{m}$ thick polystyrene film, which is placed in front of the IR beam.

SFG experiments probing the reference hydrocarbon gas species at the surfaces of oxide substrates were performed using a custom-built chamber consisting of a fused silica or $\alpha$-alumina window (ISP Optics, IR grade) clamped upon a Teflon cell holding $\mu$ l amounts of liquid hydrocarbon with a void space above it which fills with the equilibrium vapor 
pressure of the hydrocarbon molecules of interest (Fig. 1b). The SFG studies probing individual impactor samples from the central Amazon and filter samples from Southern Finland and the Harvard Environmental Chamber were carried out by clamping them between a fused silica window (ISP Optics, IR grade) and a microscope slide for backside support (Fig. 1c). Prior to each experiment the optical windows were cleaned by rinsing with methanol and by sonication in methanol for $3 \mathrm{~min}$, followed by rinsing with Millipore water and sonication in Millipore water for $5 \mathrm{~min}$. The windows were then dried in a $100^{\circ} \mathrm{C}$ oven for at least $30 \mathrm{~min}$ and subjected to 15 min of plasma cleaning (Harrick Plasma, Plasma Cleaner PDC-32G) in 300-500 $\mathrm{m}$ Torr of air prior to beginning an SFG experiment. Following plasma cleaning and cooling to room temperature, the window was placed atop the filter of interest, which was stored in a freezer at $-10^{\circ} \mathrm{C}$ until the beginning of the SFG experiments. SFG spectra of Teflon filters containing synthetic $\alpha$-pinene-derived aerosol particles, prepared as described in the experimental section, are invariant in the frequency positions of the vibrational resonances but show a 10 to $25 \%$ reduction in signal strength in the $\mathrm{CH}$ stretching region. We conclude from this result that the chemical composition of the samples, as determined by SFG, is qualitatively the same after several months of storage under these conditions. Given the $30 \mu \mathrm{m}$ spot size of our laser beams and the average mass on the filters, we calculate that there is less than one nanogram of material sampled in each of the SFG experiments. In general, we found that shorter sample collection times resulted in less material that was visibly present on the filters, and those filters yielded higher SFG signal intensity, consistent with negligible selfabsorption of the visible SFG signals by colored material on the filter (vide infra).

\section{Results}

\subsection{Vibrational responses of reference compounds}

Vibrational SFG spectra of aliphatic hydrocarbons can show up to five peaks in the $\mathrm{CH}$ stretching region, and the assignment of the vibrational resonances is very well established (Dollish et al., 1974; Bellamy, 1975; Guyot-Sionnest et al., 1987b; Roeges, 1994; Sefler et al., 1995; Nanjundiah et al., 2005; Esenturk et al., 2006; Voges et al., 2007a). Specifically important for this work, methyl $\mathrm{CH}$ stretches are identified as follows: asymmetric $\mathrm{CH}_{3}$ stretching modes generally appear in the $2945 \mathrm{~cm}^{-1}$ to $2975 \mathrm{~cm}^{-1}$ range, symmetric $\mathrm{CH}_{3}$ stretching modes appear between 2870 and $2890 \mathrm{~cm}^{-1}$, and $\mathrm{CH}_{3}$ Fermi resonances are located between 2915 and $2945 \mathrm{~cm}^{-1}$. Conversely, methylene $\mathrm{CH}$ stretching modes can appear in vibrational SFG spectra at the following frequencies: asymmetric $\mathrm{CH}_{2}$ stretching modes appear in the range 2920-2940 $\mathrm{cm}^{-1}$ and symmetric $\mathrm{CH}_{2}$ stretching modes appear between 2840 and $2870 \mathrm{~cm}^{-1}$. In this present work, we present the first vibrational SFG spectra of atmospherically relevant terpenes and secondary organic aerosol material formed from them, which we assign by combining the existing literature data with the general practice that symmetric stretches and Fermi resonances are $180^{\circ}$ out of phase with respect to their corresponding asymmetric stretches when they are probed using the SSP polarization (Lu et al., 2004; Moad et al., 2004). The following section provides a brief overview of the theoretical background of our spectroscopic measurement technique.

Figure 2 shows the SSP-polarized vibrational SFG spectra of fused silica windows in contact with the equilibrium vapor pressure over a drop of (+)- $\alpha$-pinene, (+)- $\beta$-pinene, $(-)$-limonene, isoprene, cis-2-pentene, $n$-hexene, $n$-pentene, cyclohexene, and cyclopentene maintained at room temperature, respectively. Using this polarization combination, which does not probe for chirality, there is a negligible difference between the spectra obtained from the enantiomers of neat $\alpha$-pinene, $\beta$-pinene, and limonene. The SSP polarization combination probes the components of the vibrational modes that are oriented perpendicularly to the surface. We find the SFG spectra of the cyclic terpenes to be dominated by an intense peak in the asymmetric methyl $\mathrm{CH}$ stretching region above $2900 \mathrm{~cm}^{-1}$. This finding is consistent with the fact that the three methyl groups are tightly interlocked in the bridged six-membered ring structure. Given the rigid structure of $\alpha$-pinene, the relative position of the oscillators is quite inflexible, and the SFG response is a result of strongly coupled coherences, which is consistent with the fact that we obtain a higher signal-to-noise for the terpenes than for more flexible systems such as hexane, pentane, cyclohexane, or cyclopentane (Buchbinder et al., 2010b), which have similar vapor pressures at room temperature and, given their general hydrophobic nature, thus most likely a similar surface coverage. Figure 2 also shows that the $\mathrm{CH}$ stretches of the two methyne and methylene $\mathrm{CH}$ stretches, which should occur at $2900 \mathrm{~cm}^{-1}$ and 2920 and $2850 \mathrm{~cm}^{-1}$, respectively, are not resolved in the $\alpha$-pinene spectrum shown. Other polarization combinations show negligible signal intensity in those frequency ranges as well. We conclude from these results that the SFG spectrum of (+)- $\alpha$-pinene exhibits just the asymmetric and symmetric methyl $\mathrm{CH}$ stretches at $2960 \mathrm{~cm}^{-1}$ and $2880 \mathrm{~cm}^{-1}$ as well as a methyl Fermi resonance at $2940 \mathrm{~cm}^{-1}$, which dominates the spectral response. In $\alpha$-and $\beta$-pinene, the methylene asymmetric stretch of the $\mathrm{CH}_{2}$ on the four-membered ring may be shifted to higher frequencies $\left(2950-2990 \mathrm{~cm}^{-1}\right)$ due to ring strain, and contribute to the signal observed in this range (Galabov et al., 1972; Durig et al., 1990, 2008; Ball, 1997; Buchbinder et al., 2010a).

The frequencies of the methyl $\mathrm{CH}$ stretches of $(+)-\alpha-$ pinene, $(+)-\beta$-pinene, and ( $(-)$-limonene are indicative of the substitution pattern in the six-membered ring: the asymmetric methyl CH stretch for $\beta$-pinene occurs at $2940 \mathrm{~cm}^{-1}$, whereas it occurs at $2954 \mathrm{~cm}^{-1}$ for limonene, and at 
$2938 \mathrm{~cm}^{-1}$ for $\alpha$-pinene. This finding indicates that the presence of the two methyl groups bound to the four-membered ring of $\alpha$ - and $\beta$-pinene, whose four carbon atoms are all $\mathrm{sp}^{3}$ hybridized, can be clearly identified separately of the methyl groups in limonene, which are connected to $\mathrm{sp}^{2}$-hybridizied carbon atoms. The asymmetric and symmetric methyl $\mathrm{CH}$ stretching modes of limonene occur at frequencies that are in good agreement with those reported by Belkin et al. (2007) showing vibrational SFG in chiral bulk liquids (Belkin et al., 2000), including (+)- and (-)-limonene. In the next section, the use of vibrational SFG to study secondary aerosol particles derived from isoprene and $\alpha$-pinene is presented to demonstrate how synthetic aerosol particles can be readily analyzed for their chemical composition and structural aspects by SFG.

While the olefinic $\mathrm{CH}$ stretches, which occur above $3000 \mathrm{~cm}^{-1}$ due to the $\mathrm{sp}^{2}$-hybridization state of the carbon atoms involved, are absent in the SFG spectra of the cyclic terpenes, they are clearly observed for the case of cyclopentene and isoprene, the latter of which also shows the well-known asymmetric and symmetric $\mathrm{CH}$ stretches between $2950 \mathrm{~cm}^{-1}$ and $2850 \mathrm{~cm}^{-1}$, respectively. The vibrational SFG spectra of cis-2-pentene, n-hexene, n-pentene, cyclohexene, and cyclopentene vapor in contact with an $\alpha$-alumina optical window, which have been analyzed, assigned, and discussed in our previous work (Buchbinder et al., 2010b), show substantial signal intensity in the symmetric $\mathrm{CH}$ stretching region below $2900 \mathrm{~cm}^{-1}$, and this unique response distinguishes those compounds from the terpenes.

\subsection{Vibrational responses of model and natural secondary aerosol particles}

Figure 3 shows the SSP-polarized vibrational SFG spectra of a fused silica window in contact with the equilibrium vapor pressure over a drop of (+)- $\alpha$-pinene maintained at room temperature (spectrum a) along with the SFG spectrum of a Teflon filter containing secondary organic aerosol particles prepared from (+)- $\alpha$-pinene as discussed above (spectrum b). Like the $\alpha$-pinene SFG spectrum, the SFG response is dominated by one peak, which now occurs at $2950 \mathrm{~cm}^{-1}$, while the SFG signal contribution at $2880 \mathrm{~cm}^{-1}$ is not shifted from that of unreacted $\alpha$-pinene. In addition, the SFG spectrum of the $\alpha$-pinene-derived secondary organic aerosol particles on the filter exhibits some signal contribution at $2920 \mathrm{~cm}^{-1}$, which is characteristic of methylene asymmetric $\mathrm{CH}$ stretches in alkyl chains (Voges et al., 2004; Buchbinder et al., 2010b). Given the strong asymmetric $\mathrm{CH}$ stretching contributions observed for the $\alpha$-pinenederived secondary organic aerosol particles, we conclude that the chemical composition of the particles is related to that of $\alpha$-pinene in the sense that it contains rigidly arranged methyl groups. This result is consistent with reports showing the presence of four-membered ring motifs (Tolocka et al., 2004; Docherty et al., 2005; Kroll et al., 2008; Heaton et al., 2009) in pinene-derived secondary organic material. We note that there are no other volatile organic compounds injected besides $\alpha$-pinene in the environmental chamber during the aerosol particle synthesis.

Figure 3 shows that the vibrational SFG spectrum of $\alpha$ pinene-derived secondary organic material matches almost quantitatively the vibrational SFG spectrum of PM1 filter samples collected in Southern Finland (spectrum c). This latter spectrum is the average of ten SFG spectra recorded of individual filter samples collected on the dates mentioned previously (17 July 2010, 21 July 2010, and 23 July 2010), which show little variation in the particular polarization combination (SSP) used here. While the SFG spectra of the $\alpha$ pinene-derived secondary organic material agrees very well with the vibrational SFG spectrum of PM1 filter samples collected in Southern Finland, we cannot conclude at this time that the hydrocarbon component of the material collected in the submicron size range on the filters is dominated by $\alpha$ pinene-derived secondary organic aerosol particles, mainly because $\beta$-pinene was also present in the gas phase during the time of the HUMPPA-COPEC-2010 campaign (Table 1).

Figure 3 also shows the SSP-polarized vibrational SFG spectra of a fused silica window in contact with the equilibrium vapor pressure over a drop of isoprene maintained at room temperature (spectrum d) along with the SFG spectrum of a Teflon filter containing secondary organic aerosol particles prepared from isoprene as discussed above (spectrum e). This latter spectrum shows the presence of the methyl asymmetric and symmetric $\mathrm{CH}$ stretching modes characteristic of aliphatic linear and branched hydrocarbons (Esenturk et al., 2004a; Fourkas et al., 2007), which suggests that the isoprene-derived secondary organic material consists of oligomeric or polymeric organic material in which the methyl groups are not nearly as rigidly arranged as in the $\alpha$-pinene-derived model secondary organic aerosol particles. Shown next is the vibrational SFG spectrum that is obtained from MOUDI impactor substrates containing aerosol particles with aerodynamic diameters of $1.0 \mu \mathrm{m}$ and below that were collected in the central Amazon Basin (spectrum f). The spectrum shows clear asymmetric $\mathrm{CH}$ stretching modes above $2900 \mathrm{~cm}^{-1}$ and little signal in the symmetric $\mathrm{CH}$ stretching region below $2900 \mathrm{~cm}^{-1}$. The spectrum is distinctly different from the $\alpha$-pinene and isoprene-derived model secondary organic aerosol material prepared in the environmental chamber, and it shows no immediate resemblance to the SFG spectra of the hydrocarbon species shown in Fig. 2. Given that the gas phase at the sampling site contains many hydrocarbon species during the wet season, including $\beta$-pinene and limonene, which were speciated during AMAZE-08 (Table 1), we conclude from the SFG spectrum of the $1 \mu \mathrm{m}$ sized secondary organic aerosol particles that none of the reference compounds whose SFG spectra are shown in Fig. 2 dominate the chemical composition of the natural particles from the tropical forest. However, we note that the synthetic isoprene-derived SOA particles were 


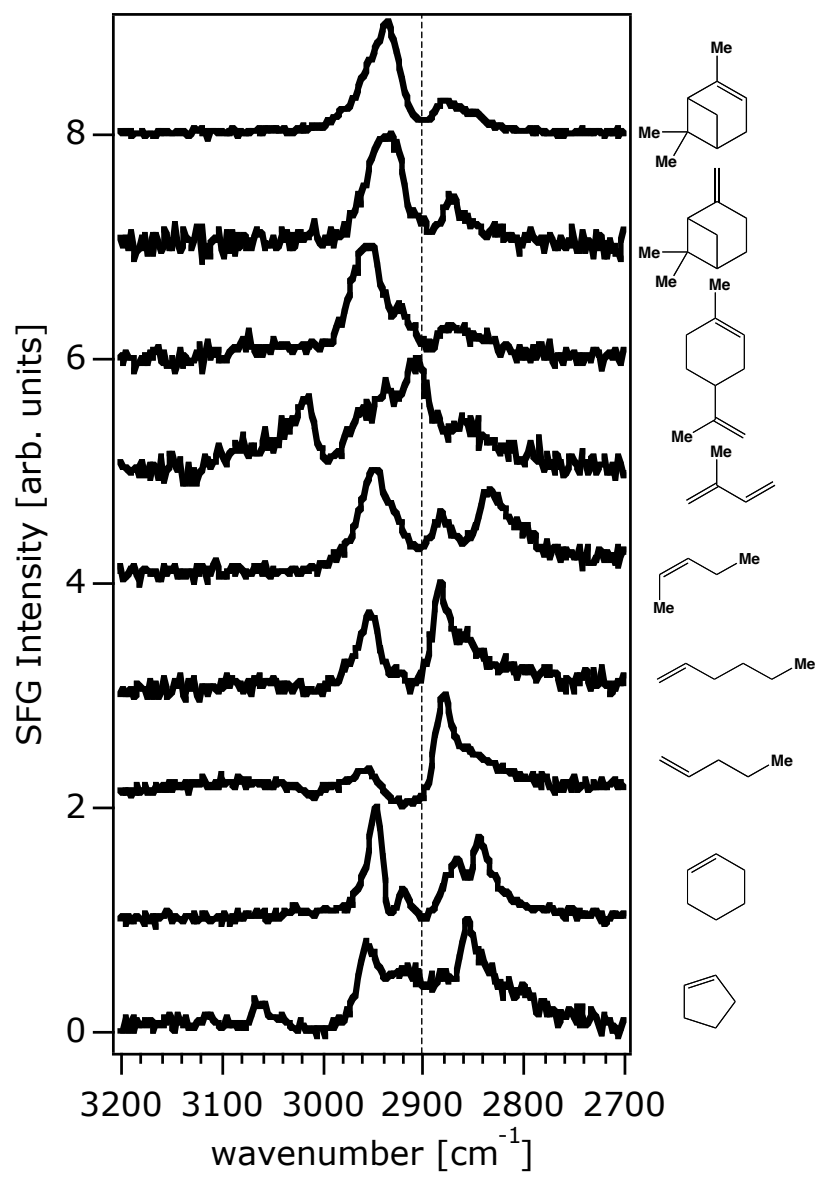

Fig. 2. SSP-Polarized vibrational SFG spectra of an optical window in contact with the equilibrium organic vapor at room temperature of (top to bottom) $\alpha$-pinene, $\beta$-pinene, limonene, isoprene, cis-2-pentene, $\mathrm{n}$-hexene, $\mathrm{n}$-pentene, cyclohexene, and cyclopentene. All spectra normalized to the highest peak intensity, and offset for clarity. The vertical dashed line at $2900 \mathrm{~cm}^{-1}$ dissects the frequency location of asymmetric and symmetric $\mathrm{CH}$ stretching modes of aliphatic hydrocarbon species to the left and right of it, respectively.

prepared at $40 \% \mathrm{RH}$, i.e. below the deliquescence $\mathrm{RH}$ of the ammonium sulfate seed particles. Given that the formation of isoprene SOA particles on deliquesced vs. "dry" seeds is expected to be mechanistically different since most isoprene oxidation products are volatile but water-soluble, the different RH conditions could contribute to the observed differences in the SFG spectra of the submicron Amazon aerosols as compared to the lab aerosols.

\subsection{Nucleation event}

As mentioned in the introduction, 23 July 2010 was characterized by an apparent nucleation event. Although a maximum likelihood of nucleation event occurrence is during spring with a secondary peak in the fall, some events also take place during the summertime (Kulmala et al., 2004; Sogacheva et al., 2005). On 23 July 2010, back-trajectories indicated that air masses arriving at Hyytiälä originated from the Arctic Ocean. Consequently the submicron aerosol number concentration decreased to a campaign minimum at 06:00 a.m. LT (Fig. 4a) (Williams et al., 2011). Although the number concentration was due to the freshly formed nanoparticles, the mass, while small, was due to the few accumulation mode particles. Due to low mass loading, the Teflon filter collected on 23 July, during the probable nucleation event, resulted in infrared absorbances, as determined by FTIR, below detection limit $\left(<1 \times 10^{-4}\right)$ in the $\mathrm{CH}$ stretching region. However, during the $6 \mathrm{~h}$ of particle collection, which sampled $2.85 \mathrm{~m}^{3}$ of air, enough particles were deposited on the filter that SFG spectra could be recorded in the $\mathrm{CH}$ stretching region. In fact, Fig. $4 \mathrm{~b}$ shows that the SSP-polarized vibrational SFG spectrum obtained from the filter collected during the first $6 \mathrm{~h}$ of the nucleation event, while less intense as expected from the smaller number density of aerosol particles sampled, is spectrally similar to that of the particles collected between roughly 06:00 a.m. 21 July 2010 and 06:00 a.m. 22 July 2010, for which transmission FTIR spectra show absorbances around $10^{-2}$. These results indicate that vibrational SFG spectroscopy can be qualitatively useful at the very low loadings associated with nucleation events.

\subsection{Size-dependence of vibrational response}

To further investigate the progression of chemical complexity in the aerosol particles collected in the central Amazon basin we recorded vibrational SFG spectra of super- and submicron sized particle fractions (Fig. 5). These spectra show strong SFG signal contributions in the aromatic $\mathrm{CH}$ stretching region above $3000 \mathrm{~cm}^{-1}$ and in the symmetric $\mathrm{CH}$ stretching region below $2900 \mathrm{~cm}^{-1}$ for the supermicron size range, and remarkably uniform spectral responses in the asymmetric $\mathrm{CH}$ stretching region above $2900 \mathrm{~cm}^{-1}$ for the submicron range. From this result and the results presented in the previous section, we conclude that while the chemical composition of the submicron size fraction is not simply isoprene-, pinene-, or limonene-like in terms of the methyl $\mathrm{CH}$ stretching signal contributions to the vibrational SFG signals, it is invariant with particle diameter in the climate-relevant submicron size range, at least for the aerodynamic diameters studied here (i.e. $50 \%$ cutoff diameters of $330 \mathrm{~nm}$ to $1.0 \mu \mathrm{m}$ ). The new spectral features obtained from the supermicron particles, when compared to the SFG spectra obtained from the submicron particles, are attributed to the presence of chemically complex primary biological material in the supermicron size range. 


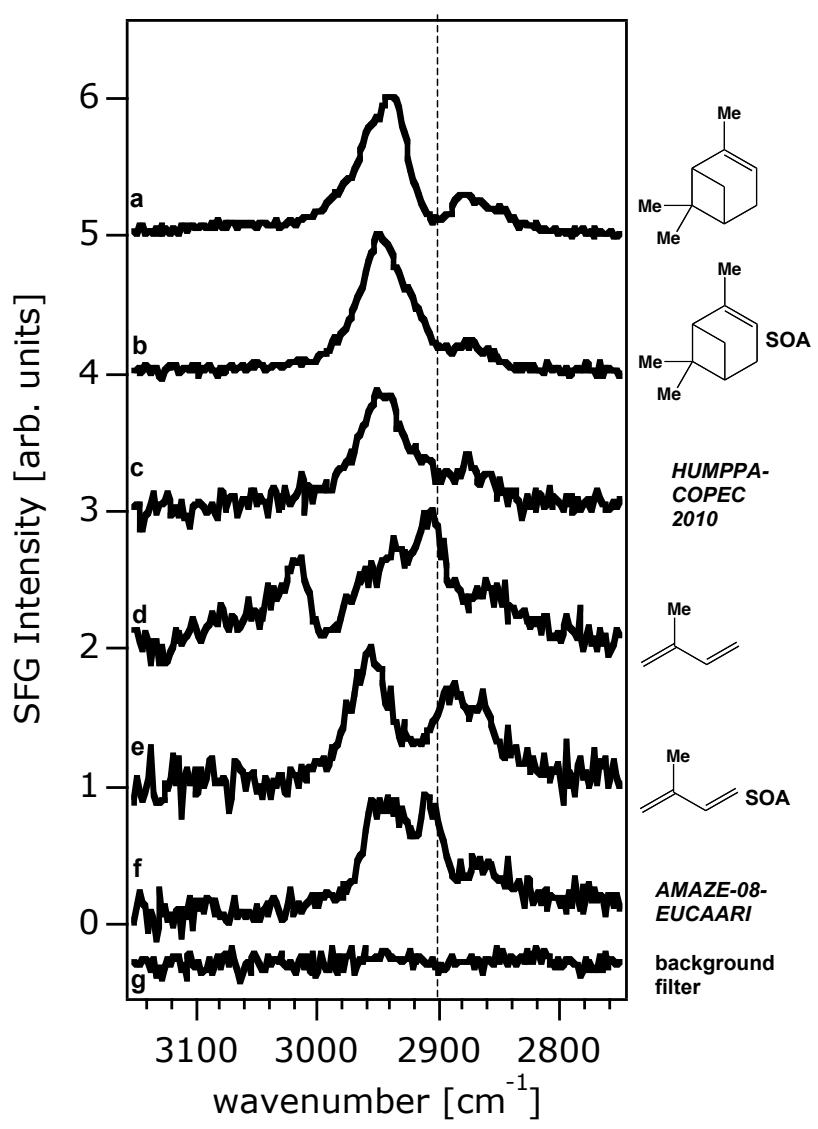

Fig. 3. SSP-Polarized vibrational SFG spectra of an optical window in contact with (a) the equilibrium organic vapor at room temperature of $\alpha$-pinene; (b) secondary organic particle material produced from $\alpha$-pinene in the Harvard Environmental Chamber (HEC); (c) a Teflon filter containing aerosol particles with diameters below $1 \mu \mathrm{m}$ collected in Southern Finland during the HUMPPACOPEC-2010 field intensive; (d) the equilibrium organic vapor at room temperature of isoprene; (e) isoprene-derived secondary organic aerosol particle material produced at the HEC; (f) a fused silica window which had been pressed against impactor substrates containing aerosol particles with diameters below $1 \mu \mathrm{m}$ collected in the central Amazon Basin during the 2008 wet season; and (g) of a Teflon filter placed after a HEPA filter during the outflow of $\alpha$-pinene-derived secondary organic aerosol particles produced at the HEC. All spectra normalized to the highest peak intensity, and offset for clarity. The vertical dashed line at $2900 \mathrm{~cm}^{-1}$ dissects the frequency location of asymmetric and symmetric $\mathrm{CH}$ stretching modes of aliphatic hydrocarbon species to the left and right of it, respectively.

\section{Conclusions}

In conclusion, we have presented vibrational sum frequency generation spectra of atmospherically relevant monoterpenes and isoprene and secondary organic aerosol material formed from them in an environmental chamber as well as in the natural environment of a boreal and a tropical forest. We
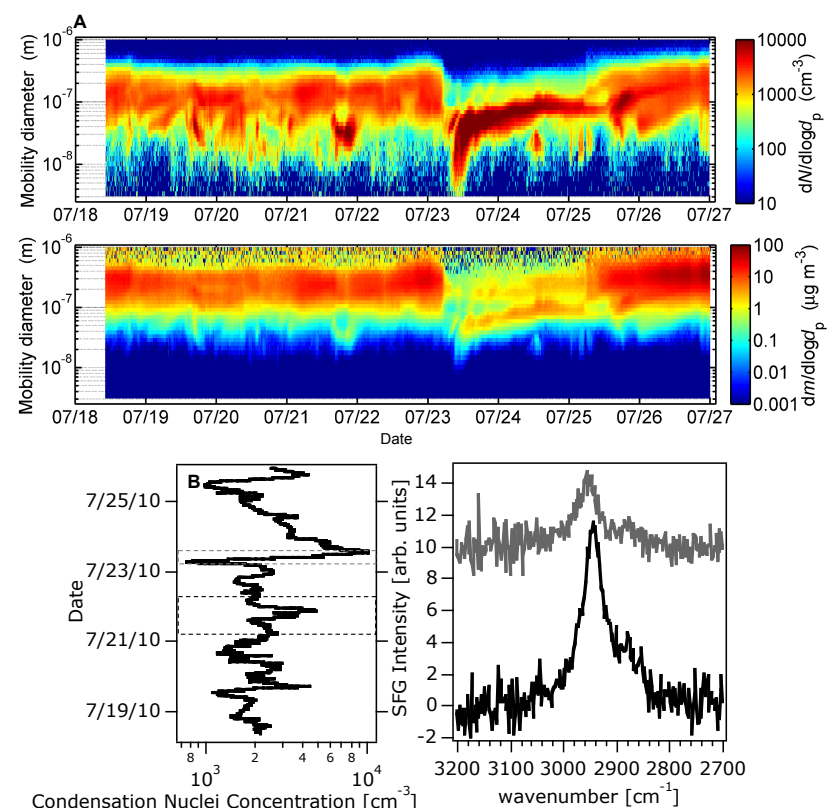

Fig. 4. (A) Aerodynamic mobility diameter and particle number density (top) and aerodynamic mobility diameter and mass particle size distribution (bottom) as a function of time of submicron-sized aerosol particles. (B) (Left) Total concentration of condensation nuclei in a supersaturated condensation chamber for the first week of the HUMPPA-COPEC-2010 campaign. The dashed boxes indicate the start and stop times for Teflon sampling filters FIN134 - 23 July 2010 (top) and FIN126 - 21 July 2010 (bottom), which sampled ambient air before (bottom) and during (top) a nucleation event. (Right) SSP-Polarized vibrational SFG spectra of a fused silica window pressed against filter FIN134 (top) and FIN126 (bottom). The SFG spectra are normalized to the same signal to noise ratio in the nonresonant frequency region to show the change in signal yield from the filter with the lower particle mass.

have evaluated how the chemical identity of the aerosol particle phase sampled in two very different geographic locations can be analyzed directly on impactor substrates and filter materials, without the need for solid phase extraction or other sample manipulation. The technique presented here exhibits sensitivities to nanogram amounts of material that offers off-line spectroscopic analysis at a time resolution that would enable greater insight into the temporal evolution of atmospheric processes, including events associated with particle nucleation, for which particle concentrations are prohibitively low for more traditional particle analysis methods. We note that the SFG spectra presented here are not reported for quantitative analysis, but future work will expand this method for the quantification of calibrated mass.

By comparing coherent vibrational spectra of a variety of terpene and olefin reference compounds as well as model secondary aerosol particle materials synthesized in an environmental chamber, we show that submicron aerosol particles sampled in Southern Finland during 


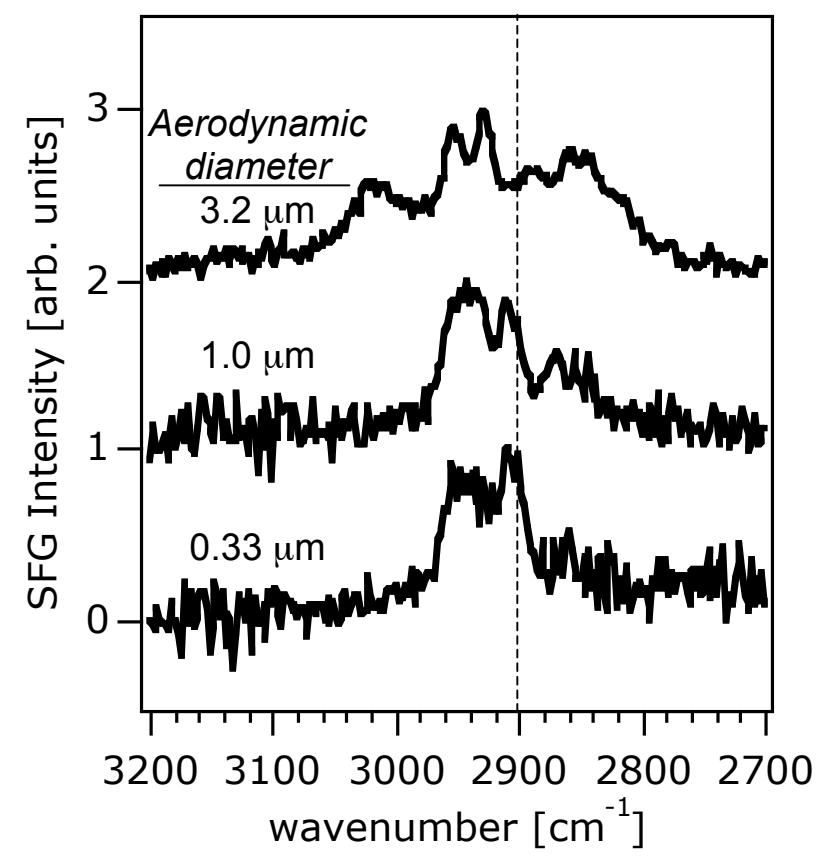

Fig. 5. SSP-Polarized vibrational SFG spectra of an optical window in contact with impactor substrates containing aerosol particles having (top to bottom) aerodynamic diameters of 3.2,1.0, and $0.33 \mu \mathrm{m}$ that were collected in the central Amazon basin during the 2008 wet season. All spectra normalized to the highest peak intensity, and offset for clarity. The vertical dashed line at $2900 \mathrm{~cm}^{-1}$ dissects the frequency location of asymmetric and symmetric $\mathrm{CH}$ stretching modes of aliphatic hydrocarbon species to the left and right of it, respectively.

HUMPPA-COPEC-2010 are composed to a large degree of material whose hydrocarbon content, as identified in the $\mathrm{CH}$ stretching region, is consistent with that of synthetic $\alpha$ pinene-derived material. Furthermore, we find that the filter sample collected during a nucleation event during the campaign exhibits a coherent vibrational spectral response that is comparable to the one obtained from particles collected in the entire submicron size fraction. Consistent with work by Riipinen et al. (2011), this finding suggests that the condensable vapors associated with the growth of the nucleation and Aitken modes, rather than continued aerosol phase chemical reactions, are involved in processes that lead to the mass increase of the particles that goes along with the increases in aerodynamic size. Given that the SSP-polarized SFG spectra report on $\mathrm{CH}$ oscillators located at the surface of the aerosol particles as opposed to those that are located in the bulk, we conclude that these growth processes introduce little or no changes in the chemical composition of the particle's surface region. While aerosol particles from the Central Amazon Basin were found to be chemically complex in the coarse mode, they exhibited similar vibrational SFG responses in the fine mode down to aerodynamic diameter as

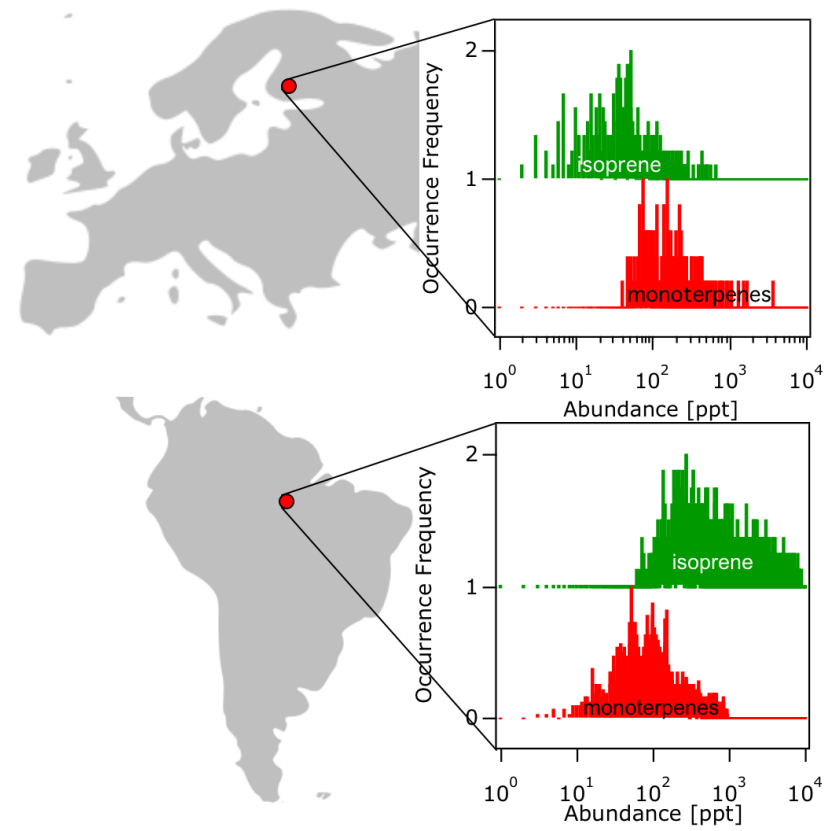

Fig. 6. Normalized histograms of the isoprene and monoterpene concentrations recorded in Southern Finland during the HUMPPACOPEC-2010 field intensive (top) and in the central Amazon basin during the 2008 wet season (bottom). Isoprene data offset for clarity in each histogram.

low as 0.33 microns, indicating that their chemical composition also changes little in the submicron size range.

These results regarding the chemical composition of organic aerosol particles formed in monoterpene- and isoprenerich air, respectively, are consistent with histogram analyses of the isoprene and monoterpene abundance recorded during the HUMPPA-COPEC-2010 and AMAZE-08 campaigns (Fig. 6). We conclude that if air is rich in monoterpenes, including $\alpha$ - and $\beta$-pinene, secondary aerosol particles that form under normal $\mathrm{OH}$ and $\mathrm{O}_{3}$ concentration levels can be described in terms of their hydrocarbon content as being similar to $\alpha$-pinene-derived model secondary organic aerosol particles in the submicron size range. Isoprene, on the other hand, undergoes reaction pathways for which $\mathrm{OH}$ radical chemistry is very important (Atkinson et al., 1998), and if the isoprene concentration dominates the chemical composition of air in a forest environment, the hydrocarbon component of secondary organic material in the submicron size range is not simply well-represented by that of isoprene-derived model secondary organic aerosol particles but is more complex. Throughout the climate-relevant aerodynamic size range of the fine mode, however, we find that the chemical composition of the secondary organic particle material from such air is remarkably invariant with size, even given the log-normal aerodynamic size distributions of a MOUDI (Marple et al., 1991), suggesting that the particle growth does not change the chemical composition of the 
hydrocarbon component of the particles in a significant way. The differences we observe in the SSP-polarized SFG spectra obtained from particles collected in the boreal vs. tropical forest environments are due to differences in the chemical composition of the particle's surfaces. These differences are likely to be due to a combination of differences in the chemical identity of the hydrocarbon precursors, the $\mathrm{O}_{3} / \mathrm{OH}$ ratio, the relative humidity, and potentially differences in $\mathrm{NO}$ concentrations in the two forest environments, among others. The findings presented here deepen our understanding of the formation, microphysics, and fate of aerosol particles in tropical vs. boreal forests in that they provide molecular information that could heretofore only be obtained with destructive methods or techniques that require extensive sample manipulation, signal averaging, or micrograms of material.

Acknowledgements. CJE gratefully acknowledges an NSF Graduate Research Fellowship. ALC acknowledges a DOE Office of Science Graduate Fellowship. JW acknowledges support from the European Community Research (ERC) Infrastructure Action Contract No RII3-CT-2006-026140 Infrastructure for Measurements, ERC Grant ATMNUCLE (project No 227463), Academy of Finland Center of Excellence program (project No 1118615), the European Integrated Project on Aerosol Cloud Climate and Air Quality Interactions EUCAARI (project No 036833-2), the EUSAAR TNA (project No 400586), and the IMECC TA (project No 4006261). PA acknowledges the support of FAPESP and CNPq for grants that funded part of this work. STM thanks the Office of Science (BES), USA Department of Energy, for support under grant No DE- FG02-08ER64529 and gratefully acknowledges support from the USA National Science Foundation under grant \# NSF ATM-0723582. LMR acknowledges support from the National Science Foundation Atmospheric Geospace Science division under grant \# NSF ATM-0904203. FMG thanks the NSF Atmospheric and Geospace Science division for support under grant \# NSF ATM-0533436 and the division of Chemical, Bioengineering, Environmental and Transport systems, Catalysis and Biocatalysis CBET program (grant \# NSF CBET 0931701), and the Northwestern University Institute for Catalysis in Energy Processes, which is funded by the Chemical Sciences, Geosciences, and Biosciences Division, Office of Basic Energy Sciences, Office of Science, USA Department of Energy (\# DE-FG02-03-ER15457). The authors also thank Spectra Physics, a Division of Newport Corporation, for equipment loans and donations as well as superb technical support. FMG gratefully acknowledges support from an I. M. Klotz professorship in physical chemistry.

Edited by: D. Heard

\section{References}

Allen, H. C., Gragson, D. E., and Richmond, G. L.: Molecular structure and adsorption of dimethyl sulfoxide at the surface of aqueous solutions, J. Phys. Chem. B., 103, 660-666, 1999.

Atkinson, R. and Arey, J.: Atmospheric chemistry of biogenic organic compounds, Acc. Chem. Res., 31, 574-583, 1998.

Ball, D. W.: Density functional calculations on the heats of formation of cyclic hydrocarbons, J. Mol. Struc-Theochem, 417 107115, 1997.

Belkin, M. A., Kulakov, T. A., Ernst, K. H., Yan , L., and Shen, Y. R.: Sum-frequency vibrational spectroscopy on chiral liquids: A novel technique to probe molecular chirality, Phys. Rev. Lett., 85, 4474-4477, 2000.

Bellamy, L. J.: The Infra-red Spectra of Complex Molecules, New York, John Wiley \& Sons, 1975.

Buchbinder, A. M., Weitz, E., and Geiger, F. M.: Pentane, Hexane, Cyclopentane, Cyclohexane, 1-Hexene, 1-Pentene, cis2-Pentene, Cyclohexene, and Cyclopentene at Vapor/alphaAlumina and Liquid/alpha-Alumina Interfaces Studied by Broadband Sum Frequency Generation, J. Phys. Chem, C., 114, 554-566, 2010a.

Buchbinder, A. M., Weitz, E., and Geiger, F. M.: Pentane, Hexane, Cyclopentane, Cyclohexane, 1-Hexene, 1-Pentene, cis2-Pentene, Cyclohexene, and Cyclopentene at Vapor/alphaAlumina and Liquid/alpha-Alumina Interfaces Studied by Broadband Sum Frequency Generation, J. Phys. Chem. C., 114, 554-566, 2010b.

Chen, Q., Liu, Y., Donahue, N. M., Shilling, J. E., and Martin, S. T.: Particle-Phase Chemistry of Secondary Organic Material: Modeled Compared to Measured O:C and H:C Elemental Ratios Provide Constraints, Env. Sci. Technol. ,asap article, 45, 4763-4770, 2011.

Chen, X., Wang, J., Boughton, A. P., Kristalyn , C. B., and Chen, Z.: Multiple Orientation of Melittin inside a Single Lipid Bilayer Determined by Combined Vibrational Spectroscopic Studies, J. Am. Chem. Soc., 129, 1420-1427, 2007.

Docherty, K. S., Wu, W., Kim, Y. B., and Ziemann, P. J.: Contributions of Organic Peroxides to Secondary Aerosol Formed from Reactions of Monoterpenes with O3 ES\&T, 39, 4049-4059, 2005.

Dollish, F. R., Fateley, W. G., and Bentley, F. F.: Characteristic Raman Frequencies of Organic Compounds, New York, John Wiley \& Sons, 1974.

Durig, J. R., Lee, M. J., and Little, T. S.: Spectra and structure of small ring compounds, Part LVI - Raman and far-infrared spectra, conformational stability vibrational assignments, normal coordinate analysis and $a b$ initio calculations of chlorocyclobutane, J. Raman Spectrosc., 21, 529-542, 1990.

Durig, J. R., El Defrawy, A. M., Ward, R. M., Guirgis, G. A., and Gounev, T. K. Gounev.: Conformational stability of chlorocyclohexane from temperature-dependent FT-IR spectra of xenon solutions, $r(0)$ structural parameters, and vibrational assignment, Struc. Chem., 19, 579-594, 2008.

Ebben, C. J., Zorn, S. R., Lee, S.-B.,Artaxo, P., Martin , S. T., and Geiger, F. M.: Stereochemical Transfer to Atmospheric Aerosol Particles Accompanying the Oxidation of Biogenic Volatile Organic Compound, Geophys. Res. Lett., 38, L16807, doi:10.1029/2011g1048599, 2011.

Esenturk, O. and Walker, R. A.: Surface Structure at Hexadecane 
and Halo-hexadecane Liquid/Vapor Interfaces, J. Phys. Chem. B., 108, 10631-10635, 2004a.

Esenturk, O. and Walker, R. A.: Surface Structure at Hexadecane and Halo-hexadecane Liquid/Vapor Interfaces, J. Phys. Chem. B., 108, 10631-10635, 2004b.

Esenturk, O. and Walker, R. A.: Surface vibrational structure at alkane liquid/vapor interfaces, J. Chem. Phys., 125, 174701, doi:10.1063/1.2356858, 2006.

Fourkas, J. T., Walker, R. A., Can, S., and Gershgoren, E.: Effects of Reorientation in Vibrational Sum Frequency Spectroscopy, J. Phys. Chem. C., 111, 8902-8915, 2007.

Galabov, B. and Simov, D.: Stretching vibrations of methylene group and ring strain in cycloalkanes, J. Mol. Struc., 11, 341346, 1972.

Geiger, F. M.: Second harmonic generation, sum frequency generation, and c(3): dissecting environmental interfaces with a nonlinear optical Swiss army knife, Annu. Rev. Phys. Chem., 60, 61-83, 2009.

Gopalakrishnan, S., Liu, D., Allen, H. C., Kuo, M. and Shultz, M. J.; Vibrational Spectroscopic Studies of Aqueous Interfaces: Salts, Acids, Bases, and Nanodrops, Chem. Rev., 106, 11551175, 2006.

Guyot-Sionnest, P., Hunt, J. H., and Shen, Y. R.: Sum-frequency vibrational spectroscopy of a Langmuir film: study of molecular orientation of a two-dimensional system, Phys. Rev. Lett., 59, 1597-1600, 1987a.

Guyot-Sionnest, P., Hunt, J. H., and Shen, Y. R.: Sum-frequency vibrational spectroscopy of a Langmuir film: Study of molecular orientation of a two-dimentional system, Phys. Rev. Lett., 59, 1597-1600, 1987b.

Hayes, P. L., Chen, E. H., Achtyl, J. L., and Geiger, F. M.: An Optical Voltmeter for Studying Cetyltrimethylammonium Interaction with Fused Silica/Aqueous Interfaces at High Ionic Strength, J. Phys. Chem. A., 113, 4269-4280, 2009.

Heaton, K. J., Sleighter, R. L., Hatcher, P. G., Hall IV, W. A., and Johnston, M. V.: Composition Domains in Monoterpene Secondary Organic Aerosol, Environ. Sci. Technol., 43, 7797-7802, 2009.

Holzinger, R., Williams, J., Herrmann, F., Lelieveld, J., Donahue, N. M., and Röckmann, T.: Aerosol analysis using a ThermalDesorption Proton-Transfer-Reaction Mass Spectrometer (TDPTR-MS): a new approach to study processing of organic aerosols, Atmos. Chem. Phys., 10, 2257-2267, doi:10.5194/acp10-2257-2010, 2010.

Karl, T., Guenther, A., Yokelson, R. J., Greenberg, J. P., Potosnak, M., Blake, D. R., and Artaxo, P.: The tropical forest and fire emissions experiment: Emission, chemistry, and transport of biogenic volatile organic compounds in the lower atmosphere over Amazonia, J. Geophys. Res., 112, D18302, doi:10.1029/2007jd008539, 2007.

Konek, C. T., Musorrafiti, M. J., Al-Abadleh, H. A., Bertin, P. A., Nguyen, S. T., and Geiger, F. M.: Interfacial Acidities, Charge Densities, Potentials, and Energies of Carboxylic AcidFunctionalized Silica/Water Interfaces Determined by Second Harmonic Generation, J. Am. Chem. Soc., 126, 11754-11755, 2004.

Kroll, J. H. and Seinfeld, J. H.: Chemistry of secondary organic aerosol: Formation and evolution of low-volatility organics in the atmosphere, Atmos. Env., 42, 3593-3624, 2008.
Kulmala, M., Vehkamaki, H., Petaja, T., Dal Maso, M., Lauri, A., Kerminen, V. M., Birmili, W., and McMurry, P. H.: Formation and growth rates of ultrafine atmospheric particles: a review of observations, J. Aerosol Sci., 35, 143-176, 2004.

Lelieveld, J., Butler, T. M., Crowley, J. N., Dillon, T. J., Fischer, H., Ganzeveld, L., Harder, H., Lawrence, M. G., Martinez, M., Taraborrelli, D., and Williams, J.: Atmospheric oxidation capacity sustained by a tropical forest, Nature, 452, 737-740, 2008.

Liu, D. F., Ma, G., Levering , L. M., and Allen, H. C.: Vibrational Spectroscopy of aqueous sodium halide solutions and air-liquid interfaces: Observation of increased interfacial depth, J. Phys. Chem. B., 108, 2252-2260, 2004.

Lu, R., Gan, W., Wu, B.-H., Chen, H., and Wang, H.-F.: Vibrational Polarization Spectroscopy of $\mathrm{CH}$ Stretching Modes of the Methylene Group at the Vapor/Liquid Interfaces with Sum Frequency Generation, J. Phys. Chem. B., 108, 7297-7306, 2004.

Marple, V. A., K. L. Rubow and S. M. Behm. A Microorifice Uniform Deposit Impactor (MOUDI): Description, Calibration, and Use Aerosol Science and Technology, Phys. Chem. Chem. Phys., 14, 434-446, 1991.

Martin, S. T., Andreae, M. O., Althausen, D., Artaxo, P., Baars, H., Borrmann, S., Chen, Q., Farmer, D. K., Guenther, A., Gunthe, S. S., Jimenez, J. L., Karl, T., Longo, K., Manzi, A., Müller, T., Pauliquevis, T., Petters, M. D., Prenni, A. J., Pöschl, U., Rizzo, L. V., Schneider, J., Smith, J. N., Swietlicki, E., Tota, J., Wang, J., Wiedensohler, A., and Zorn, S. R.: An overview of the Amazonian Aerosol Characterization Experiment 2008 (AMAZE-08), Atmos. Chem. Phys., 10, 11415-11438, doi:10.5194/acp-1011415-2010, 2010.

Martinez, I. S., Peterson, M. D., Ebben, C. J., Hayes, P. L., Artaxo, P., Martin, S. T., and Geiger, F. M.: On molecular chirality within naturally occurring secondary organic aerosol particles from the central Amazon basin, Phys. Chem. Chem. Phys., 13, 1211412122, 2011.

Moad, A. J. and Simpson, G. J.: A Unified Treatment of Selection Rules and Symmetry Relations for Sum-Frequency and Second Harmonic Spectroscopies, J. Phys. Chem. B., 108, 3548-3562, 2004.

Mucha, M., Frigato, T., Levering, L. M., Allen, H. C., Tobias, D. J., Dang, L. X., and Jungwirth, P.L: Unified Molecular Picture of the Surfaces of Aqueous Acid, Base, and Salt Solutions, J. Phys. Chem. B., 109, 7617-7623, 2005.

Nanjundiah, K. and Dhinojwala, A.: Confinement-Induced Ordering of Alkanes between an Elastomer and a Solid Surface, Phys. Rev. Lett., 95, 154301, doi:10.1103/PhysRevLett.95.154301, 2005.

Riipinen, I., Pierce, J. R., Yli-Juuti, T., Nieminen, T., Häkkinen, S., Ehn, M., Junninen, H., Lehtipalo, K., Petäjä, T., Slowik, J., Chang, R., Shantz, N. C., Abbatt, J., Leaitch, W. R., Kerminen, V.-M., Worsnop, D. R., Pandis, S. N., Donahue, N. M., and Kulmala, M.: Organic condensation: a vital link connecting aerosol formation to cloud condensation nuclei $(\mathrm{CCN})$ concentrations, Atmos. Chem. Phys., 11, 3865-3878, doi:10.5194/acp-11-38652011, 2011.

Roeges, N. P. G.: A Guide to the Complete Interpretation of Infrared Spectra of Organic Structures, New York, John Wiley \& Sons, 1994.

Sander, S. P., Abbate, J., Barker, J. R., Burkholder, J. B., Friedl, R. R., Golden, D. M., Huie, R. E., Kolb, C. E., Kurylo, M. J., 
Moortgat, G. K., Orkin, V. L., and Wine, P. H.: Chemical Kinetics and Photochemical Data for Use in Atmospheric Studies, Evaluation No. 17. J. P., 10-6, Pasadena, CA, JPL, 2011.

Sefler, G. A., Du, Q., Miranda, P. B., and Shen, Y. R.: Surface crystallization of liquid n-alkanes and alcohol monolayers studied by surface vibrational spectroscopy, Chem. Phys. Lett., 235, 347354, 1995.

Shilling, J. E., Chen, Q., King, S. M., Rosenoern, T., Kroll, J. H., Worsnop, D. R., McKinney, K. A., and Martin, S. T.: Particle mass yield in secondary organic aerosol formed by the dark ozonolysis of ?-pinene, Atmos. Chem. Phys., 8, 2073-2088, doi:10.5194/acp-8-2073-2008, 2008.

Sogacheva, L., Dal Maso, M., Kerminen, V. M., and Kulmala, M.: Probability of nucleation events and aerosol particle concentration in different air mass types arriving at Hyytiala southern Finland, based on back trajectories analysis, Boreal Environ. Res., 10, 479-491, 2005.

Stokes, G. Y., Buchbinder, A. M., Gibbs-Davis, J. M., Scheidt, K. A., and Geiger, F. M.: Chemically diverse environmental interfaces and their reactions with ozone studied by sum frequency generation, Vibrat. Spec., 50, 86-98, 2009a.

Stokes, G. Y., Chen, E. H., Buchbinder, A. M., Paxton, W. F., Keeley, A., and Geiger, F. M.: Atmospheric Heterogeneous Stereochemistry, J. Am. Chem. Soc., 131, 13733-13737, 2009.

Stokes, G. Y., Chen, E. H., Walter, S. R., and Geiger, F. M.: Two Reactivity Modes in the Heterogeneous Cyclohexene Ozonolysis under Tropospherically Relevant Ozone-Rich and OzoneLimited Conditions, J. Phys. Chem. A., 113, 8985-8993, 2009c.

Tarbuck, T. L. and Richmond, G. L.: Adsorption and Reaction of $\mathrm{CO} 2$ and SO2 at a Water Surface., J. Am. Chem. Soc., 128, 3256-3267, 2006.

Tolocka, M. P., Jang, M., Ginter, J. M., Xoc, F. J., Kamens, R. M., and Johnston, M. V.: Formation of oligomers in secondary organic aerosol, Stokes, G. Y., Chen, E. H., Buchbinder, A. M., Paxton, W. F., Keeley, A., and Geiger, F. M.: Atmospheric Heterogeneous Stereochemistry, Environ. Sci. Technol., 38, 14281434, 2004.

Tyrode, E., Rutland, M. W., and Bain, C. D.: Adsorption of CTAB on Hydrophilic Silica Studied by Linear and Nonlinear Optical Spectroscopy, J. Am. Chem. Soc., 130, 17434-17445, 2008.

Voges, A. B., Al-Abadleh, H. A., Musorrariti, M. J., Bertin, P. A., Nguyen, S. T., and Geiger, F. M.: Carboxylic acid- and ester-functionalized siloxane scaffolds on glass studied by broadband sum frequency generation, J. Phys. Chem. B., 108, 1867518682, 2004.

Voges, A. B., Al-Abadleh , H. A., and Geiger, F. M.: Development of Nonlinear Optical Spectroscopies for Studying Heterogeneous Environmental Catalytic Processes, Environmental Catalysis. V. H. Grassian, Boca Raton, FL, CRC Press, 2005a.

Voges, A. B., Al-Abadleh, H. A., and Geiger, F. M.: Applications of Non-Linear Optical Techniques for Studying Heterogeneous Systems Relevant in the Natural Environment, Environmental Catalysis, Grassian, V. H., Boca Raton, FL, 2005b.
Voges, A. B., Stokes, G. Y., Gibbs-Davis, J. M., Lettan, R. B., Bertin, P. A., Pike, R. C., Nguyen, S. T., Scheidt, K. A., and Geiger, F. M.: Insights into Heterogeneous Atmospheric Oxidation Chemistry: Development of a Tailor-Made Synthetic Model for Studying Tropospheric Surface Chemistry, J. Phys. Chem. C., 111, 1567-1578, 2007a.

Voges, A. B., Stokes, G. Y., Gibbs-Davis, J. M., Lettan, R. B., Bertin, P. A., Pike, R. C., Nguyen, S. T., Scheidt, K. A., and Geiger, F. M.: Insights into Heterogeneous Atmospheric Oxidation Chemistry: Development of a Tailor-Made Synthetic Model for Studying Tropospheric Surface Chemistry, Invited Feature Article in J. Phys. Chem. C., 111, 1567-1578, 2007 b.

Voss, L. F., Bazerbashi, M. F., Beekman, C. P., Hadad, C. M., and Allen, H. C.: Oxidation of Oleic Acid at Air/Liquid Interfaces, J. Geophys. Res., 112, D06209, doi:10.1029/2006jd007677, 2007.

Wang, H.-F., Gan, W., Lu, R., Rao, Y., and Wu, B.-H.: Quantitative spectral and orientational analysis in surface sum frequency generation vibrational spectroscopy (SFG-VS), Int. Rev. Phys. Chem., 24, 191-256, 2005.

Weeraman, C., Yatawara, A. K., Bordenyuk, A. N., and Benderskii, A. V.: Effect of Nanoscale Geometry on Molecular Conformation: Vibrational Sum-Frequency Generation of Alkanethiols on Gold Nanoparticles, J. Am. Chem. Soc., 128, 14244-14245, 2006.

Williams, J., Crowley, J., Fischer, H., Harder, H., Martinez, M., Petäjä, T., Rinne, J., Bäck, J., Boy, M., Dal Maso, M., Hakala, J., Kajos, M., Keronen, P., Rantala, P., Aalto, J., Aaltonen, H., Paatero, J., Vesala, T., Hakola, H., Levula, J., Pohja, T., Herrmann, F., Auld, J., Mesarchaki, E., Song, W., Yassaa, N., Nölscher, A., Johnson, A. M., Custer, T., Sinha, V., Thieser, J., Pouvesle, N., Taraborrelli, D., Tang, M. J., Bozem, H., Hosaynali-Beygi, Z., Axinte, R., Oswald, R., Novelli, A., Kubistin, D., Hens, K., Javed, U., Trawny, K., Breitenberger, C., Hidalgo, P. J., Ebben, C. J., Geiger, F. M., Corrigan, A. L., Russell, L. M., Ouwersloot, H., Vilà-Guerau de Arellano, J., Ganzeveld, L., Vogel, A., Beck, M., Bayerle, A., Kampf, C. J., Bertelmann, M., Köllner, F., Hoffmann, T., Valverde, J., González, D., Riekkola, M.-L., Kulmala, M., and Lelieveld, J.: The summertime Boreal forest field measurement intensive (HUMPPA-COPEC-2010): an overview of meteorological and chemical influences, Atmos. Chem. Phys. Discuss., 11, 1592115973, doi:10.5194/acpd-11-15921-2011, 2011.

Zhu, X. D., Suhr, H. J., and Shen, Y. R.: Surface Vibrational Spectroscopy by Infrared-Visible Sum-Frequency Generation, J. Opt. Soc. America B-Optical Physics, 3, 252, 1986. 